healthy. I am indebted to Mr. Fraser for help in obtaining the notes of this case. Amongst other things this case suggests that it may be necessary to wash out and drain the lesser sac. This could best be done by tearing through the great omentum below the stomach. An exploration through Winslow's foramen might determine the necessity for this step, which, after all, is not a very serious one.

In concluding the notes of these cases it is interesting to remark that in one the ulcer was easily and securely closed, and the patient's life prolonged rather than shortened, and that the other ulcers could likewise have been closed had they been diagnosed. So far as can be judged in anomalous cases the diagnosis can as yet only be correctly made through an incision. A small exploratory incision through the linea alba above the umbilicus is such a trifling addition to the risks of such cases that it seems to be reasonable in future to try it. The kind of case would be one in which laparotomy had shown that diffuse septic peritonitis existed in the lower abdomen, with no recognisable or probable cause there. Upper Berkeley-street, $\mathrm{W}$.

\section{LANDERER'S METHOD OF TREATING FRACTURES.}

BY JOSIEPH LUMNICZER, M.D.

UP to a comparatively recent date one has been unable to shorten the time required for the healing of a fracture. While the treatment of compound fractures has been completely changed by the antiseptic method, so that brilliant results have been attained, the treatment of simple fractures has been almost untouched by the progress of science. For the treatment of fractures Landerer has introduced a new therapeutic method easy of application and excellent in its results. In the Second Surgical Clinic in Budapest, from 1880 to 1891, 552 simple fractures were observed, and from these the following data were obtained. To fix the time of healing of a fracture two dates can be taken - viz.: (1) the time when the callus between the ends of the broken bone has fully developed, so that no abnormal mobility can be detected, and (2) the time when the functional activity of the limb is restored. The time when the patient is discharged from the hospital is of little value as a criterion of the time required for healing, as many personal and local circumstances influence it greatly. The return of fanctional activity of the limb is the surest test of the time required for the healing of a fracture. In general the time required for the complete return of functional activity after the bones had joined formed from onethird to two-thirds of the time occupied in the junction of the fragments. It was not always possible to fir the moment of return of functional activity in fractures of the upper limb, as many patients were discharged as soon as the bones had joined, and were treated as out-patients; but in fractures of the lower extremity the patients remained under observation until completely healed.

From a consideration of these data it was evident that the slighter bones need less time than the larger ones. In the cases observed the longest time for union was required in a case of fracture of the femur (57 days), and the shortest with a fracture of the metatarsus (23 days) and clavicle (24 days), in the forearm and fibula ( 35 days), in the tibia (39 days), and in the patella (52 days, chiefly fibrous union). After the union of the bones a farther period was needed-viz., for the patella 83 days, the femur 81 days, the humerus and tibia 62 days, the fibula 59 days, and the uIn and clavicle 39 days. The average further period required for active mobility amounted in the forearm to only half the time needed for union of the bones-namely, 15 to 32 days; elsewhere it takes about two-tbirds-viz. in the case of the clavicle, radius, and ulna from 15 to 17 days; and in the humerus and femur 28 to 30 days. With a slight inaccuracy we can get the time of commencement of functional mobility if we add to the time requiced for consolidation 15 days for the clavicle and bones of the forearm and 30 days for the humerus and bones of the lower extremity.

Landerer's method, as described below, was the outcome of an attempt to shorten the healing time of fractures. According to this method (1) the ends of the bone are to be replaced immediately after the fracture and to be fixed in a firm dressing (such as plaster-of-Paris) until the disappearance of the swelling due to the injury ; and (2) when the soft provisional callus is fully formed (which takes place in from eight to fourteen days) the callus and the surrounding muscles are to be massaged twice a day-at first gently, but later more energetically ; and the mobility of the neighbouring joints is to be kept ap by active and passive movements. When this is done it is noticed that the callus, which during the first few days was soft and yielding, soon hardens and becomes strong, and the neighbouring joints, at first somewhat stiff, rapidly recover their original mobility. This treatment was employed in 93 cases at the Second Surgical Clinic-i.e., in 89 cases of simple and 4 cases of compound fracture. In all these cases special care was used to determine accurately the date of union of the bones, and also the date of return of complete functional activity. In the compound fractures, after rendering the wounds aseptic and applying dressings, the fractures were put up, and in from two to three weeks the soft parts had made such progress that passive movements and massage conld be employed, and the results were as satisfactory as in the case of simple fractures.

The general results of this treatment may be summarised as follows. Fixation of the bones took in general from 12 to 36 days, the shortest time being 12 days for the clavicle and the longest 57 for the femur. Functional activity was attained in 14 days for the clavicle, but took 51 days for the femur. The time between consolidation and functional activity generally was not more than 10 days, with the exceptions of the femur (15 days) and the bones of the forearm (13 days). These results show that with this treatment consolidation and functional activity were attained at a much earlier period than was the case under the old treatment. For consolidation under the former treatment from 24 to 57 days were required, while in the cases just referred to it varied from 12 to 36 days, the difference amounting to from 6 to 21 days. The greatest difference is found in the case of the femur and tibia, where consolidation occurred 21 and 19 days earlier respectively. But the benefit of the new treatment is still more manifest if we compare the periods required for attaining complete functional activity. Under the former treatment from 39 to 83 days were needed, but now only from 14 to 51 days. Thus by Landerer's method one effects a saving of time in consolidation of one-third and of a third also for mobility. During the period of healing one could assure oneself of the condition of the callus ; the massage perceptibly increased the rapidity of its ossification, and the stiffness of the neighbouring joints, due to the enforced resting for from six to eight days, soon disappeared, the muscles regained their elasticity, and the blood effused into the joint was quickly absorbed.

Judged by its results, the early use of massage and of passive movements is very useful. This treatment is not to be recommended in comminuted fractures or in cases where there is a very great tendency to displacement of the ends of the bones. Sometimes the massage cannot be borne more than once a day at first, but soon the tenderness disappears, and then it can be performed twice a day.

\section{THE INFLUENCE OF THE CLIMATE OH EGYPT UPON DISEASE.}

\section{BY LEIGH CANNEY, M.D. LOND.} PHYSTCIAY TO THE LUXOR HOSPITAL

THE object of this paper is to attempt to point out rather more in detail than has been done previously what morbid conditions are benefited by wintering in Egypt, what benefit may be expected, if any, and what cases are unsuitable. Some thirty years ago or more Dr. Dalrymple briefly stated the cases benefited by wintering in Egypt as phthisis (certain cases), bronchitis, asthma, renal disease, and cerebral softening. After that little more was done until Dr. Sandwith a few years ago published his interesting work, "Egypt as a Winter Resort," and added an appendix containing a list of suitable cases for Egypt. Since his work was published the numbers of people wintering in Egypt have increased, and every year makes it possible to be more and more precise in weighing the advantages to be attained in this climate. In cases of the rarer diseases evidence naturally comes slowly, and as to 
these a decision must be made at present rather on theoretical grounds, as the number of cases recorded is too small to justify a practical conclusion. But perhaps a shrewd opinion might be formed from the relative frequency of these diseases amongst the Egyptians themselves. A very large proportion of the diseases which will be found classified below as "deriving great benefit" are such as are practically unknown to the natives of the country or are but slight in their intensity. It is hoped that these lists may be helpful to those who have not been able to visit this interesting country themselves, and may lighten the responsibility which one must feel in sending a patient to a somewhat distant land. To find that the question, "Shall I get better in Egypt?", can in most cases be answered distinctly "Yes" or "No" may prove of great value to both patient and adviser, and it will be no small satisfaction to the medical adviser who has temporarily broken up a family to see his patient back again and able to endorse his opinion of six months before. The question of what part of Egypt the several and varied cases should be sent to, and the life to be led, may be dealt with subsequently, for I imagine that the prescription "Egypt" can hardly be considered sufficient in a country 1000 miles long, presenting such different conditions as are to be found in a life in Cairo, at the Pyramids or Helouan, at Luxor or Assouan (both several hundreds of miles south of Cairo), in a dahabeah or steamer on the Nile, or in a tent in the desert-all presenting variations in temperature and relative humidity, and other conditions as regards accommodation, \&c., which must not be neglected; and in all these matters the patient will do well to follow absolutely the advice of one of the physicians resident in the country.

A few instructions regarding the best method of spending the winter and the mode of life advisable would prevent such mistakes as the following: a patient sent out for diabetes, ascending the Great Pyramid, and so inducing coma and death; or a patient with valvular disease, ascending the Nile in a steamer and daily joining in a six or eight mile gallop on a donkey, the pace being at the mercy of the donkey boys and the rest of the party, and including a climb to the top of some pylon, when it might have been possible to sail placidly in a dahabeah without any alarming consequences; or might help the patient with gout, bepatic dyspepsia, and lithrmia to decide to lead a more active life ap the Nile than sitting on the balcony of a hotel in Cairo or taking a drive to the citadel to witness the sunset.

In the lists given below I have attempted to classify the cases which "derive great benefit," "some benefit," and those which are "not suitable." "This attempt combines the views of Dr. Bentley, who has resided at Mena House Hotel, Pyramids, Mr. W. Longmore, who has resided at Assouan, Dr. Sandwith of Cairo, and myself at Luxor, each having had several years' experience in Egyot; and to these gentlemen I am much indebted for so kindly placing their medical experience at my disposal, and thus adding greater weight to the opinions expressed. Doubtless the opinions of other physicians in Egypt would have thrown more light on the subject, had they been available. Of necessity there are slight differences of opinion as to some diseases, owing to the fact that the cases observed have been limited in number, perhaps, or, as in the case of diseases in which the pathology is different in different cases-e.g., " neuralgia "-if one happened to have only notes of malarial cases or rheamatic cases it would naturally appear that greater benefit had ensued than if one were only taking account of cases in which other pathological conditions predominated. But when cases have been numerous, as in phthisis, kidney disease, mental strain, \&c., the consensus of opinion points very definitely in one or other direction.

\section{Class I.-The Pathological Conditions Where The} PATIENT WILL DERIVE GREAT BENEFIT.

Phthisis : (1) non-erethic ${ }^{1}$ cases ; (2) bæmorrhagic cases ; (3) non-acute cases of first or second stage, especially commencing deposit without very acute symptoms; (4) chronic quiescent phthisis, with or without cavities ; (5) cases associated with bronchitis. Asthma : idiopathic and symptomatic. Chronic bronchitis and emphysema. Cases convalescent from pneumonia, pleuro-pneamonia, and pleurisy, especially cases following influenza where the structures have not returned to the normal state. Chronic nasal and pharyngeal catarrh, and Eustachian deafness. Cases of mental strain,

"Frethie" constitutions subject to pyrexia, rapid pulse, irritability fo mucous membrane, capricious appetite, and asthenia out of propor-
tion to the irritation or injury inflicted. breakdown, and irritability from overwork, especially such cases when associated with gout, arterio-sclerosis, fibroid kidney, atheroma, and age. Cases of hemiplegia and paresis dependent upon vascular changes other than embolism, especially those cases which are associated in etiology with the preceding class; insomnia not dependent on heart disease; Bright's disease in all its forms other than acute ; and albuminuria generally and after pregnancy. Rheumatoid arthritis, gout, and associated lithiasis and renal colic. Cases of imperfect convalescence from the acate specifics, such as scarlet fever, typhoid fever, influenza, \&c., and especially if the kidneys have been involved; dyspepsia, hepatic, and lithæmia; and rheamatic fever, after the attack.

Class II.-Whree the Patient Will DeRIVe Benefit.

Dyspepsia (chronic, atonic and chronic catarrhal); hysteria ; alcoholusm ; bypochondriasis ; neurasthenia; early cases of locomotor ataxy and sclerosis of the cerebro-spinal system ; neuralgia (of rheumatic or malarial origin); premature senility ; early valvular disease ; "functional" heart disease ; bronchiectasis; children with strumous tendency; adenoid growths; hepatic disease contracted in India, the subjects of which are returning to Furope too early in the winter; the after-results of malaria; glycosuria in gouty subjects; eczema, especially gouty forms; laryngitis and "clergyman's sore-throat" ; cystitis, those cases in which distended bladder and pressure backwards have led to commencing kidney disease; chronic ovaritis, parametritis, or perimetritis ; Hodgkin's disease ; and anæmia.

\section{Class III.-Unsuitable Cases.}

Phthisis with very acute symptoms or tendency to diarrhcea, or repeated plearisy, or involved largnx, or active disease of both lungs; advanced emphysema, with weak dilated right side of the heart; fatty heart ; angina pectoris ; hypertrophy and dilatation of the left side of the heart; aortic regurgitation and aneurysm; advanced endocarditis; dysentery or after dysentery ; chronic diarrbcea; tuberculous kidney ; psoriasis; diabetes, acute; nenralgia (other than the forms of neuralgia included in Class II.) ; advanced locomotor ataxy and nerve scleroses generally; and general paralysis of the insane.

In the above lists it might have been advisable to give an intermediate class between Class II. and Class III., where, although the climate can effect no change, or practically no change, in the disease itself, yet it may delay its further progress, or at least offer a means of happy existence that it would be hard to deny the patient. Thus, for an early case of locomotor ataxy, lateral or disseminated sclerosis, or progressive muscular atrophy, to be able to sit in a comfortable chair on the deck of a dahabeah, accompanied by one's friends and a medical adviser to add a sense of security-to be able thus to take in at a glance all the life and interest of the passing banks of the Nile, in a perfect climate ; to watch the changes of the sky and the crew at their various occupations-seems to me to offer a new life to a brain yet active enough to appreciate it, or at least to offer the patient a chance of forgetting his troubles, if not of mending them.

$I$ will now add a few remarks on individual cases in the above groups. In cases of phthisis Dr. Sandwith tells me that the opinion used to be held that hæmorrhagic cases should not be sent to Egypt, and, indeed, he would still add a certain reserve on these cases, adding the words "some cases," and I find the same opinion in Dr. Burney Yeo's work on Climate. Personally I am of opinion that, if the case is not excluded by other groups here indicated, the climate of Upper Egypt and the desert is one of the best attainable for these cases. At Luxor in three years, out of all the cases of phthisis living at the hotels and on the river that I have seen, bæmorrhage has only occurred $t$ wice, and both of these cases would have been inadmissible, being cases of acute phthisis. I have seen five medical men wintering in Egypt for this very condition, all doing well, and still living and active. With regard to asthma, some cases do better than otbers, but the major part are free from attacks, or nearly so. The benefit in cases of chronic bronchitis and cases of catarrh is sufficiently well known. I should like to draw special attention to the class of cases " mental strain and breakdown," for the importance of the climate is very marked in all these cases, and in the special cases which are associated with the pathology indicated (and where the fibroid kidney and atheroma cannot with certainty be proved the condition of the pulse and vessels and other well-known signs do not leave much doubt of their presence) the "overstrain" is removed, and business 
and the markets and "the things which go up and down in the City" are all forgotten in watching the panorama of Cairo life, lunching in the Valley of the Tombs of the Kings, or shooting the cataract. I think it is important to consider these cases in association with the subdivision "hemiplegia and paresis," for, given the same etiology, we are only one step further in the case ; and it is the great benefit the climate confers on the etiological conditions which have induced this accident that must be notedthe gout diminished, the kidneys relieved by the skin, any slight bronchitis removed by the purity and dryness of the air, a purer blood current supplied to every organ, abolishing the headache and clearing the brain, worry and strain removedall combining to make the patient feel "ten years younger" and to delay the next, or final, disaster perhaps indefinitely. That the climate cannot mend the ruptured nerve track and lift the arm again seems to me no argument why these cases should not be allowed the benefit of this climate. I have found it stated more than once that a patient with a tendency to apoplexy "cannot go to Egypt," but I believe there are strong arguments why this class at least should be sent. I am sorry that I cannot at present produce evidence as to the arterial tension and volume of blood, for I am inclined to the opinion that both may be lower in the Guropean after his recent arrival in Egypt, as it would perhaps bear on the cases just considered and might place a slight reservation on the question of aneurysm being unsuited, and perhaps add a difficulty to the cases of aortic regurgitation, thereby diminishing the advantages these latter cases might expect from increased skin action and improvement of the functions of the kidney. The advantages of the climate in cases of insomnia are to be noted, but if this be dependent on heart disease it will be only partially benefited - or perhaps not at all if the patient, ignorant of the heart trouble, spends his days in over-fatigue.

As to Bright's disease, albuminuria, rheumatoid arthritis, gout, and acute rheumatism (between the attacks) the results are so well known, the climate being practically unique in these cases-provided they live in the driest districts of Figypt-that it is not necessary to dwell longer here. Although in the opinion of Dr. Peterson of New York there is "no better climate in the world" for neuralgia of rheumatic or malarial origin, this has been placed in Class II., for the reason that, though this opinion may be, and probably is, correct, yet it is not advisable to raise hopes too high. If the patient comes in the early stages of the disease to Egypt, the cause of the disease may be removed, and one would certainly expect an arrest of its progress; but to the patient's mind, ignorant of his future and barely satisfied with a partial reduction in the severity of his present pains, there may be some disappointment if the result is overstated. Cases which do not come within the etiology indicated are not suitable. Some medical men would be inclined to place chronic dyspepsia of both varieties, especially chronic catarrhal, in Class I. The fact is that the word "indigestion" is never or rarely heard up the Nile; it must not be forgotten, however, that Egyptian cooking and some of the main articles of diet are not of the quality to be had at home, especially as regards meat. Cases of hysteria, alcoholism, and hypochonoriasis, especially if placed under direct medical supervision, would be benefited. With heart disease perhaps enough evidence to generalise is wanting, but probably aortic regurgitation is the least benefited. Functional discase of the heart is greatly improved, and those cases in which early hypertrophy and dilatation of the right side of the heart are present or to be expected would derive greater benefit than would sufferers from the same trouble on the left side. Those who have been the subjects of malaria, and staying in Egypt, would derive benefit from the climate and should spend their time in desert resorts. Laryngitis and clergyman's sore-throat must be sent to the spot the least dusty and freest from organisms and at the same time the most equable. Children with strumous tendency do very well, and cases of premature senility derive great benefit. The cases of cystitis indicated must have continued medical supervision and must not be allowed to live simply as tourists, regardless of the task to be accomplished. In Class III. "Unsuitable," most of the cases are obriously unfitted. Advanced emphysema with bronchitis and weak dilated heart is in danger everywhere. If the hotels were specially constructed and ventilated to preserve uniform conditions, these patients might avoid the changes of temperature and relative moisture which even in Egypt occasionally induce in sensitive subjects a fresh attack. We must not forget the desirability of excluding those subject to chronic diarrhoea from any cause, or the remains of dysentery, although Dr. Sandwith finds that dysentery that has been cured and sprue (hill diarrhoea) derive benefit, and he would regard Egypt as a convenient resting-place on the homeward journey from the East, in the winter months, for these cases. It is to be hoped that, as time goes on, it may be possible to deal more closely still with the exact pathology of the cases whick. derive great benefit-and this seems the more desirable as these cases seem to include a great number in which it would be difficult, if not impossible, to obtain the corresponding: relief by other methods.

Luxor.

\section{Clinital Altots:}

\section{MEDICAL, SURGICAL, OBSTETRICAL, AND THERAPEUTICAL.}

\section{CEREBRAL DEAFNESS.}

BY Robert T. COOPER, M.A., M.D. T.C.D., \&c

THERE is a form of impaired hearing remarkable for the fact that patients can hear the ticking of a watch at long distances, say at arm's length, and yet are unable or imperfectly able to hear the human voice. When a very marked disproportion exists between the two-the watch-hearing and the voice-hearing -I invariably inquire into the mental bistory of the patient and his family, and without exception in all these somewhat unusual cases I have been enabled to discover an indubitable cerebral history or to foretell cerebral involvement. It is not, of course, uncommon to find a disproportion between the watch-hearing and the voice-hearing among deaf patients, and I do not at all claim that the mere fact of an alteration of the normal ratio between the two is to be considered significant: I only claim attention for this special feature when such disproportion is very great, and when it is the voice-hearing and not the power to hear the watch that is lost. This peculiarity, admittedly, would be by itself a very insecure ground upon which to base a diagnosis, but it is, I maintain, a justifiable one upon which to found a suspicion, as it certainly does warrant fuller inquiry according to $\mathrm{my}$ experience. I must leave the prosecution of further research in the hands of those engaged in the study of cerebral disease. Some of the cases in which, in my hands, this peculiarity existed were attended with symptoms of softening of the brain ; while epilepsy, melancholia, and general inaptitude for the affairs of life I have found present, and in these cases the ages varied from fourteen to sixty. Deaf patients, without intending to do so, are very liable to deceive the examiner, and it is known that in some instances the sound of a watch will linger on the ear for a moment or two and appear to be heard when it is not; this I quite take account of in the methods adopted in testing the hearing. In spite of precautions there remains sufficient evidence to warrant me in pronouncing this a separate variety of impaired hearing, and in saying that it has in about a dozen cases been apparently indicative of cerebral disease.

George-street, Hanover-square, W.

\section{A CASE OF DISLOCATION OF THE HUMERUE WITHOUT FRACTURE IN A PATIENT NINETY- FOUR YEARS OF AGE.}

Bx W. Lenton Heath, M.D. Lond., F.R.C.S. Eng.

ON June 2nd, 1894, a woman ninety-four years of age, rather thin, but well-nourished considering her years, tripped over a rug in her room, falling on her right side and arm. She immediately felt great pain in the shoulder, and was unable to move her arm. I saw her soon after the accident and found that the head of the humerus was dislocated into the axilla; but there were no signs of fracture of the bones. The patient was so much distressed by the shock of her fall and the pain in the arm that $I$ thought it advisable to give her an anæsthetic before attempting to reduce the dislocatec 